\title{
Wetting angle stability of steel surface structures after laser treatment
}

N. Shchedrina ${ }^{1}$, Yu. Karlagina ${ }^{1}$, T. E. Itina ${ }^{1,3}$, A. $\operatorname{Ramos}^{1,2}$, D. Correa ${ }^{1,2}$, A. TokmachevaKolobova $^{4,5}$, S. Manokhin ${ }^{4}$, D. Lutoshina ${ }^{1}$, R. Yatsuk ${ }^{1}$, I. Krylach ${ }^{1}$ and G. Odintsova ${ }^{1}$ 1 ITMO University, 49 Kronverksky Pr., St. Petersburg 197101, Russia

2 Instituto Politecnico Nacional, SEPI-ESIME-Zacatenco, Ed.5, 3-r piso, Ciudad de Mexico C.P.07738, Mexico

3 Univ. Lyon, UMR CNRS 5516/UJM-Saint-Etienne, Laboratoire Hubert Curien, SaintEtienne 42000, France

4 Institute of Problems of Chemical Physics of RAS, Academician Semenov av. 1, Chernogolovka, Moscow region, 142432, Russia

5 National University of Science and Technology “MISIS”, Leninskiy pr. 4, Moscow, 119049, Russia

\begin{abstract}
In this work, we have used a nanosecond pulsed fiber laser to modify the wettability characteristics of AISI 430 steel. For this, various surface morphologies were created on the samples by laser irradiation with different overlapping and intensity parameters. Immediately upon laser treatment, all the structured samples acquired either hydrophilic or superhydrophilic wetting angles. All the samples were also analyzed with XRD. Then, laser-treated samples were kept in ambient air and/or low-temperature annealing was applied to reach hydrophobic surface properties. Interestingly, these surfaces returned back practically to their initial wetting state by cleaning in an ultrasonic bath. The obtained results are analyzed based on the existing wettability models.
\end{abstract}

\section{Introduction}

The brilliant creations of nature have always been a source of inspiration for humanity. By analyzing the morphologies and chemical compositions of animal skins and plant leaves and by following the biomimetic principle, different types of surfaces were created to achieve properties similar to the ones of biological objects. In particular, hierarchical micro- and nanostructures together with a chemical composition control were shown to considerably modify surface wettability (Huerta-Murillo et al. 2018; Long et al. 2015; Liu et al. 2011; Song et al. 2017). Either hydrophobic or hydrophilic surfaces are used in various applications, such as anti-corrosion treatment, fabrication of microfluidic 
systems, oil-water separation, friction reduction, enhancing surface self-cleaning, liquid transportation and deposition of particles (Liu and Jiang 2011). Superhydrophobic structures prevent bacteria adhesion and metal corrosion. Such surfaces are also used to decrease surface icing in humid atmosphere and under low temperature conditions (Avrămescu et al. 2018). They are also particularly promising in biomedical application in blood-contacting and non-blood contacting applications, and more specifically for medical devices (Wyman et al. 2012).

Structure modification of metal surfaces has attracted attention due to numerous industrial applications. Namely, surface micro and nanostructuring is often used to control liquid behavior on surfaces. To adjust wettability , different surface modification methods are applied in the industry, including mechanical methods, such as blasting (Lieblich et al. 2016), machining (Rotella et al. 2014), grinding (Nik et al. 2012), water jet machining (Li and Wang 2015). Additionally, chemical methods are also used including chemical coating, chemical etching (Hwang et al. 2009), hydrogen peroxide treatment (Daw et al. 2013), acid treatments (Wennerberg et al. 2013), alkali treatment (Ravelingien et al. 2010; Butev et al. 2015), and electro deposition (Yang et al. 2019). Surface texturing can be, furthermore, achieved by using noncontact processes, such as laser ablation (Chantada et al. 2017).

Alternatively, lasers also allow controlling the surface wettability of various materials, in particular of metals. It is known that immediately after laser micro-structuring of metals their surface becomes hydrophilic (Kietzig, A.M. et al. 2009; Ngo, C.V. et al. 2018; Sciancalepore, C. et al. 2018; Bizi-Bandoki, P. et al. 2013; Kietziga, A. M. et al, 2011; Ngo, C. V. et al 2017). Authors (Kietzig, A.M. et al. 2009; Sciancalepore, C. et al. 2018; Bizi-Bandoki, P. et al. 2013; Kietziga, A. M. et al, 2011) report that such surfaces acquire hydrophobic properties if structured materials are kept in ambient air. Such surfaces are of growing interest for various industrial applications, as stated above. The question arises whether these hydrophobic surfaces are stable and suitable for the industry. Previously, Kolobov, Yu.R et al (Kolobov, Yu.R et al. 2014) on the example of 
commercially pure titanium showed that 15 minutes ultrasonic cleaning in ethanol of textured by femtosecond laser surfaces leads to decreasing of the wetting angle and 15 minutes plasma cleaning in argon recovers initial superhydrophilic state.

To explain the wetting transition phenomena, different mechanisms were evoked. For example, several authors (Ngo, C.V. et al. 2018; Ngo, C. V. et al 2017) proposed a method of accelerating the transition process by lowtemperature annealing, which also leads to the formation of hydrophobic surfaces. Other authors (Kietzig A.M. et al. 2009) suggested the transition to hydrophobic state is associated with the formation of active magnetite on metal samples adsorbing carbon, which appears because of the slow decomposition of $\mathrm{CO}_{2}$ at room temperature. Ngo et al. ( Ngo et al. 2017) supported this theory and showed that low-temperature annealing accelerated this transition due to a more intense decomposition of $\mathrm{CO}_{2}$. Bizi-Bandoki et al. (Bizi-Bandoki, P. et al. 2013) claimed that the wettability transition could be explained by the appearance of new functional groups. For example, the appearance of new non-polar carbon groups $\left(-\mathrm{CH}_{3}\right.$ and graphitic carbon) on the structured aluminum surface after laser treatment was proposed as a possible explanation. Another study (Long, J. et al. 2015) suggested that surfaces acquire hydrophobic properties because of the adsorption of organic compounds from the surrounding atmosphere onto the laser produced oxide surface. Authors (Kim, D. et al. 2016) consider oxygen to be the dominant factor for the wettability transition after a series of experiments.

Despite numerous investigations, the control over surface wetting and the ways if its modification remains challenging. Therefore, herein we check the stability of several hydrophobic textured surfaces obtained by laser treatment. In particular, two methods are examined: (i) by keeping in ambient air; and (ii) lowtemperature annealing. Moreover, the influence of water on the resulting contact angles is considered.

\section{Materials and methods}

In these studies, AISI 430 steel was chosen as the main material. The experiments were conducted on $5 \times 4.5 \mathrm{~cm}$ plates with thickness of $0.5 \mathrm{~mm}$. 
The sample surface structuring was performed in air by using a system based on a nanosecond pulsed ytterbium fiber laser with a wavelength $\lambda=1.064$ $\mu \mathrm{m}$ (Laser Center Co., Ltd., Russia) generating pulses at $60 \mathrm{kHz}$ with $100 \mathrm{~ns}$ duration. The beam was focused on the target in a nearly Gaussian spot with a diameter of approximately $50 \mu \mathrm{m}$ leading to laser intensity in the range of 28.3 $\mathrm{MW} / \mathrm{cm}^{2}-282.9 \mathrm{MW} / \mathrm{cm}^{2}$. To provide a different number of pulses per spot by $\mathrm{X}$ and $\mathrm{Y}$ axis the surfaces of samples were irradiated in the air by line scanning with parallel traces using various overlapping at controlled scan rate.

Micro images of the structured surfaces of samples were obtained by using Zeiss Axio Imager A1M optical microscope. The morphology of the surfaces was studied with Zeiss Merlin scanning electron microscope. X-Ray diffraction (XRD) analysis was performed using X-Ray diffractometer ARL X'TRA with focusing according to Bragg-Brentano under the following conditions: radiation $\mathrm{Cu}-\mathrm{Ka}\left(\lambda=1.540562 \mathrm{~A}^{\circ}\right)$, scanning step $0.02^{\circ}(2 \Theta)$, scanning range $25^{\circ}-95^{\circ}(2 \Theta)$, scan rate $1.71 \% \mathrm{~min}$. The primary data were processed using PDXL software and PDF-2 database.

To measure the wetting contact angle, we designed a setup based on the LED arrangement source (summary power $1 \mathrm{~W}$ ) and high-resolution CCD camera ToupCam. Distilled water was used as a test liquid. Drop volume for measurements was $5 \mu \mathrm{l}$. After droplet deposition on the surface Digimizer software was used for contact angle measurements.

Low-temperature annealing of the samples was conducted in a PM-10 muffle furnace at temperature $100{ }^{\circ} \mathrm{C}$ for 3 hours in the air. The air humidity was measured with Extech hygro-thermometer psychrometer. The samples were cleaned in an ultrasonic bath (Sapphire) with distilled water at temperature $28{ }^{\circ} \mathrm{C}$ for 60 minutes.

\section{Results and discussion}

The effect of laser structuring of steel surface on the wetting angle.

The initial unstructured is characterized by low surface roughness and the contact angle of 69 degrees (Fig. 1). 


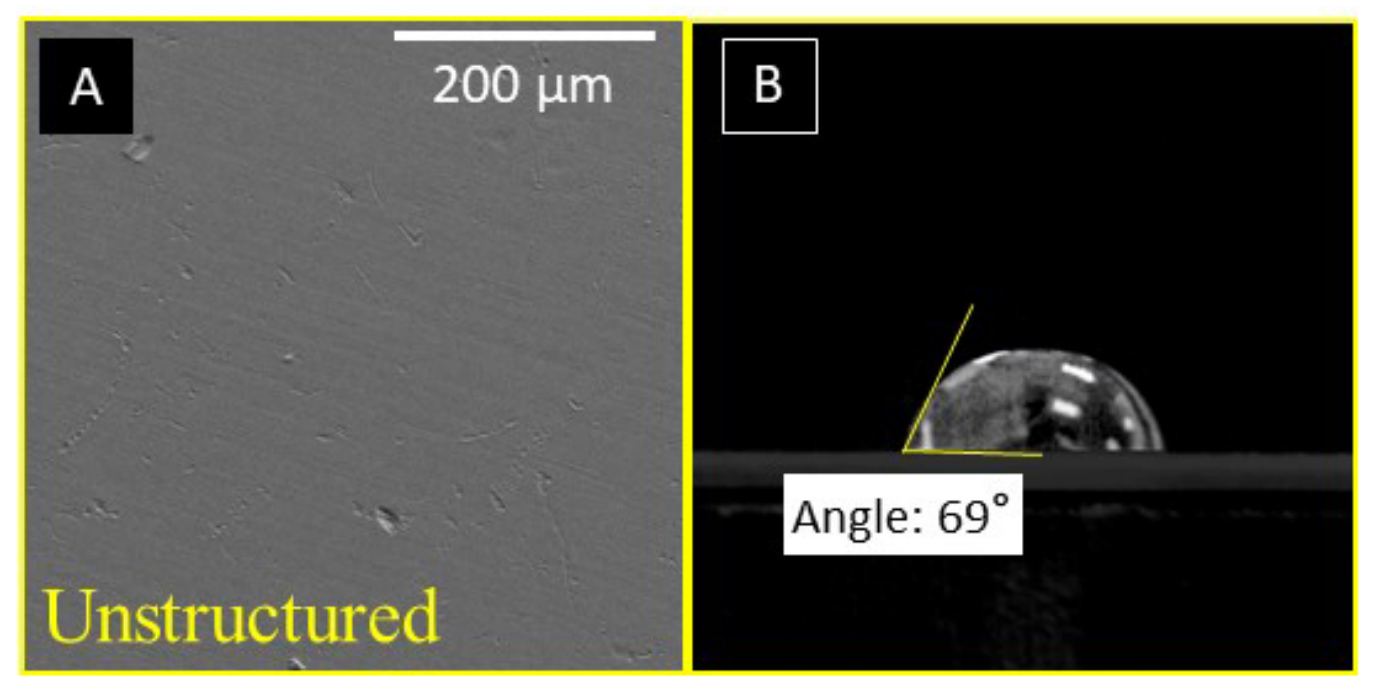

Figure 1. SEM image of an unstructured steel surface (A), contact angle is 69 degrees (B).

To consider the temperature effect on the morphology and contact angle, the intensity and the overlapping of the laser spots along the horizontal and vertical axes of the laser scanning were chosen as the parameters of the laser treatment. Changing these parameters allowed us to produce different surface structures on the surfaces of steel. To obtain various overlapping $L_{x}=L_{y}=0,30$, $60,90 \%$, and different intensity $I$ from $28.3 \mathrm{MW} / \mathrm{cm}^{2}$ to $282.9 \mathrm{MW} / \mathrm{cm}^{2}$ the laser radiation parameters were calculated using the following formulas:

$$
I=\frac{P}{\tau \times f \times \pi \times r_{0}^{2}}
$$

where $I$ is intensity, $P$ is average laser radiation power, $\tau$ is pulse duration, $f$ is pulse repetition rate, $r_{o}$ is radius of the laser beam.

$$
\begin{aligned}
& L_{x}=\left(1-\frac{v_{s c}}{f \times d}\right) \times 100 \% \\
& L_{y}=\left(1-\frac{1}{N \times d}\right) \times 100 \%
\end{aligned}
$$

where $L_{x}$ and $L_{y}$ are laser spot overlapping along the vertical and horizontal scanning axes, $d$ is diameter of the laser beam imprint on the surface of the material, $N$ is number of lines per millimeter, $v_{s c}$ is laser scan speed.

By varying laser intensity and overlapping, different surface structures were obtained on the surface of steel. SEM-images of the resulting samples are presented in Fig. 2-5. 


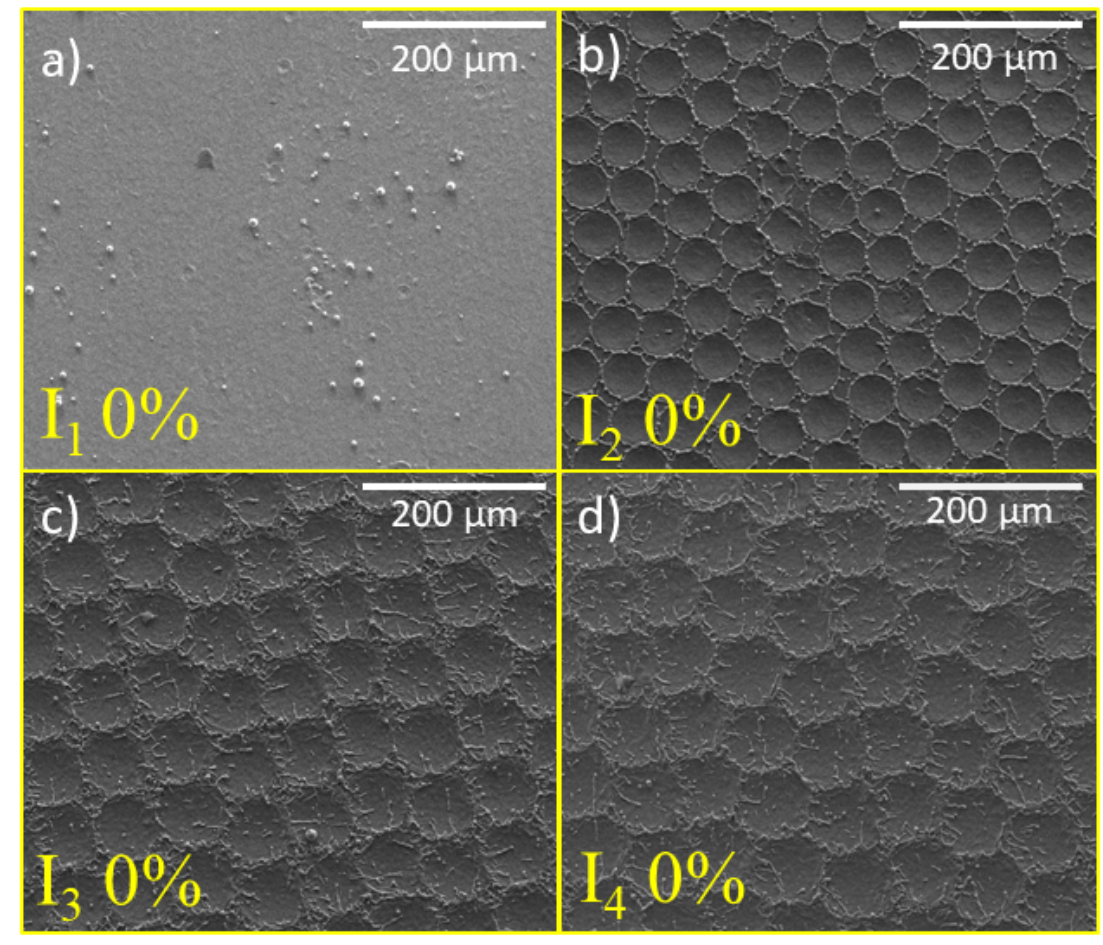

Figure 2. SEM images of laser structured samples obtained for overlapping $L_{x}=$ $\mathrm{L}_{\mathrm{y}}=0 \%$ and intensity of $\mathrm{I}_{1}=28.3 \mathrm{MW} / \mathrm{cm}^{2}(\mathrm{a}), \mathrm{I}_{2}=56.6 \mathrm{MW} / \mathrm{cm}^{2}(\mathrm{~b}), \mathrm{I}_{3}=$ $169.8 \mathrm{MW} / \mathrm{cm}^{2}(\mathrm{c}), \mathrm{I}_{4}=282.9 \mathrm{MW} / \mathrm{cm}^{2}(\mathrm{~d})$.

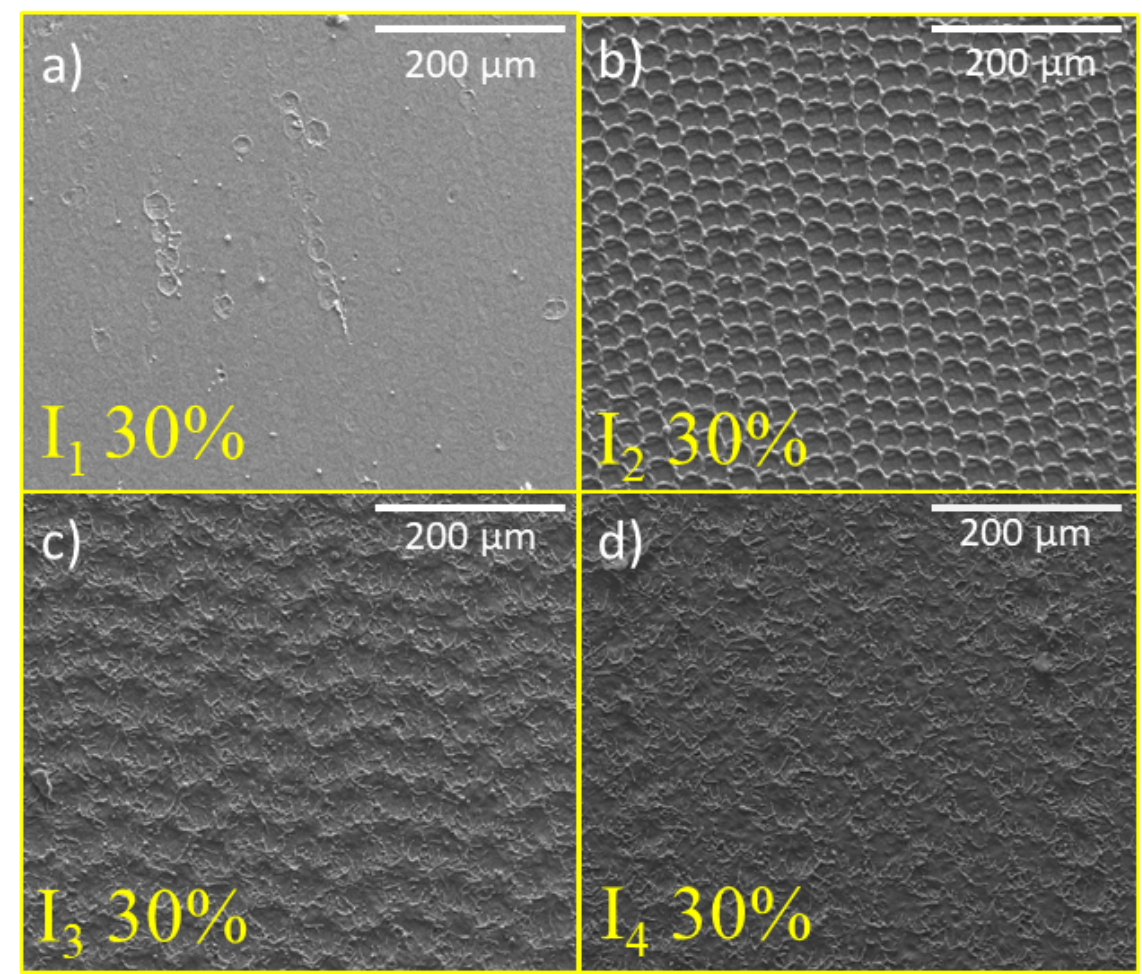

Figure 3. SEM images of laser structured samples obtained foroverlapping $L_{x}=$ $L_{y}=30 \%$ and intensity of $I_{1}=28.3 \mathrm{MW} / \mathrm{cm}^{2}(\mathrm{a}), I_{2}=56.6 \mathrm{MW} / \mathrm{cm}^{2}(\mathrm{~b}), I_{3}=$ $169.8 \mathrm{MW} / \mathrm{cm}^{2}(\mathrm{c}), I_{4}=282.9 \mathrm{MW} / \mathrm{cm}^{2}(\mathrm{~d})$. 


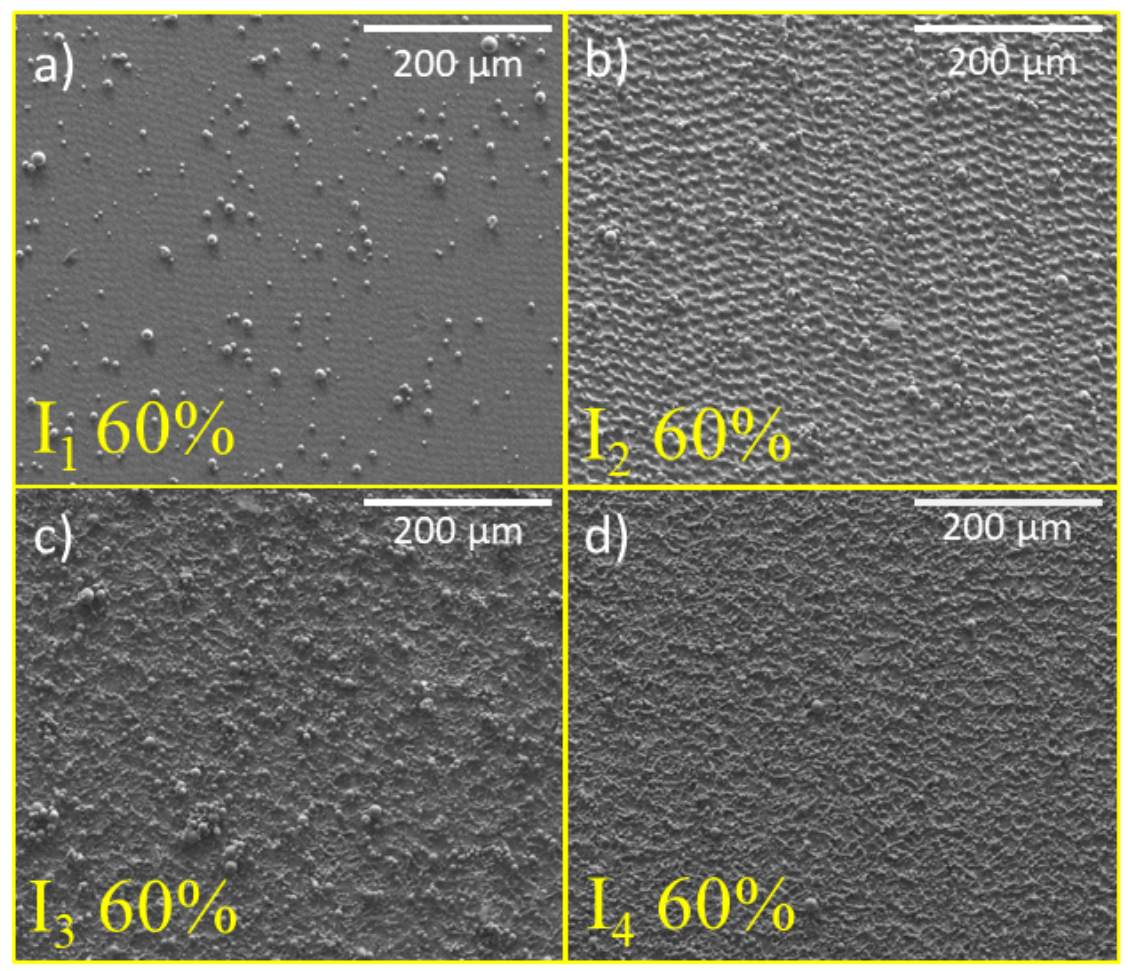

Figure 4. SEM images of laser structured samples obtained for overlapping $L x=$ $L y=60 \%$ and intensity of $I_{1}=28.3 \mathrm{MW} / \mathrm{cm}^{2}(\mathrm{a}), I_{2}=56.6 \mathrm{MW} / \mathrm{cm}^{2}(\mathrm{~b}), I_{3}=$ $169.8 \mathrm{MW} / \mathrm{cm}^{2}(\mathrm{c}), I_{4}=282.9 \mathrm{MW} / \mathrm{cm}^{2}(\mathrm{~d})$.

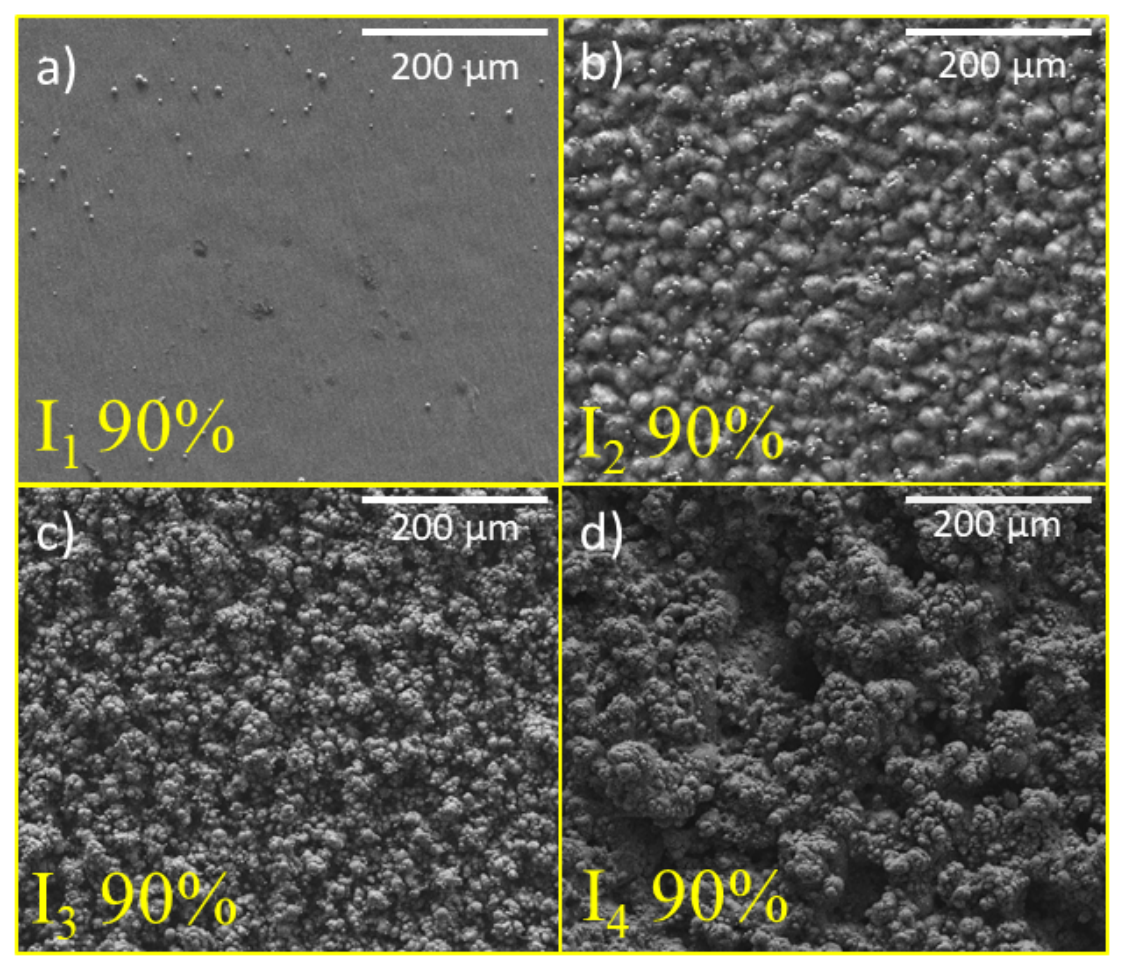

Figure 5. SEM images of laser structured samples obtained for overlapping $L_{x}=$ $L_{y}=90 \%$ and intensity of $I_{1}=28.3 \mathrm{MW} / \mathrm{cm}^{2}(\mathrm{a}), I_{2}=56.6 \mathrm{MW} / \mathrm{cm}^{2}(\mathrm{~b}), I_{3}=$ $169.8 \mathrm{MW} / \mathrm{cm}^{2}(\mathrm{c}), I_{4}=282.9 \mathrm{MW} / \mathrm{cm}^{2}(\mathrm{~d})$. 
As shown in Fig. 2-5, starting from laser intensity of $169.8 \mathrm{MW} / \mathrm{cm}^{2}$, splashes of molten material appear at the edges of the recesses formed. This change occurs due to the process of intense evaporation of the metal from the surface and leads to the appearance of a considerably deep relief.

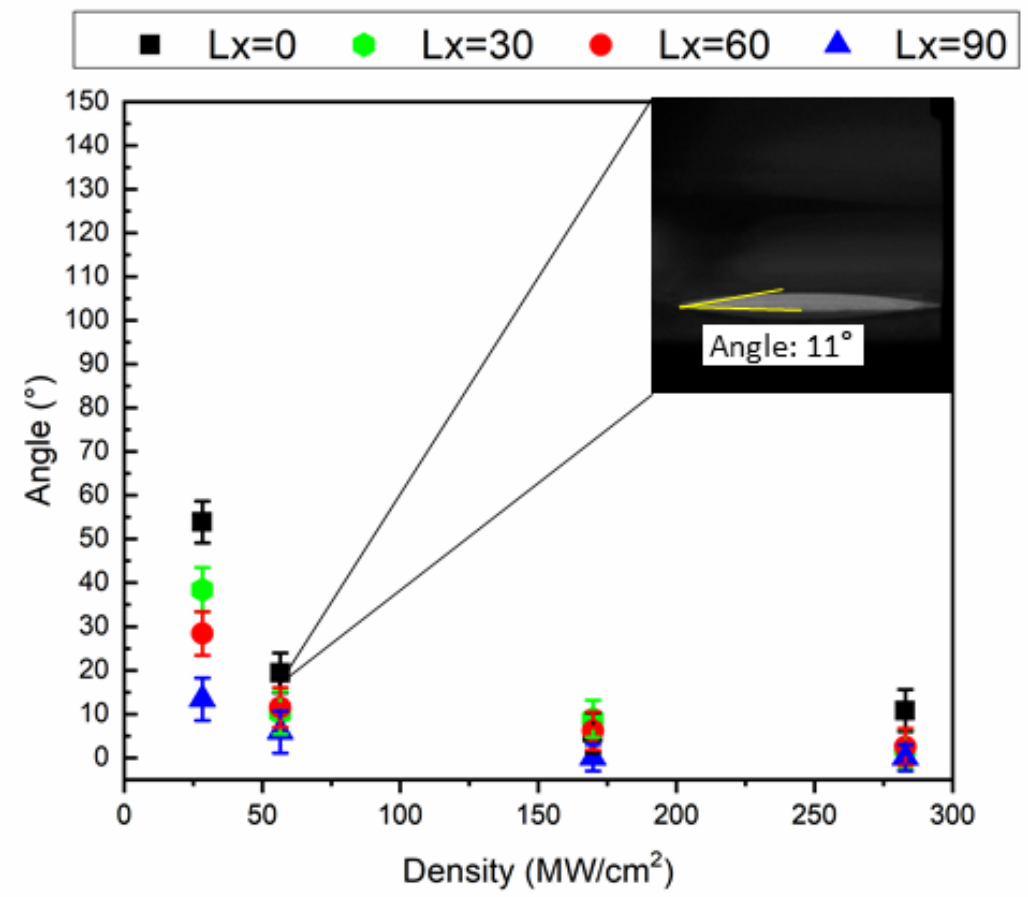

Figure 6. Dependence of contact angle on laser intensity for different overlapping right after laser structuring; $L_{x}=L_{y}$.

It should be noted that a dependence between the contact angle and laser irradiation parameters is revealed. After laser treatment, all samples show hydrophilic properties (Fig. 6). As one can see in the Figure, with the increase in laser intensity and overlapping, the contact angle tends to decrease.

The phase composition effect of structured samples on the wetting angle.

One unstructured and three structured samples $\mathrm{I}_{2} 0 \%, \mathrm{I}_{2} 60 \%, \mathrm{I}_{2} 90 \%$ with different laser parameters of irradiation are then chosen for X-ray diffraction analysis of phase composition. 


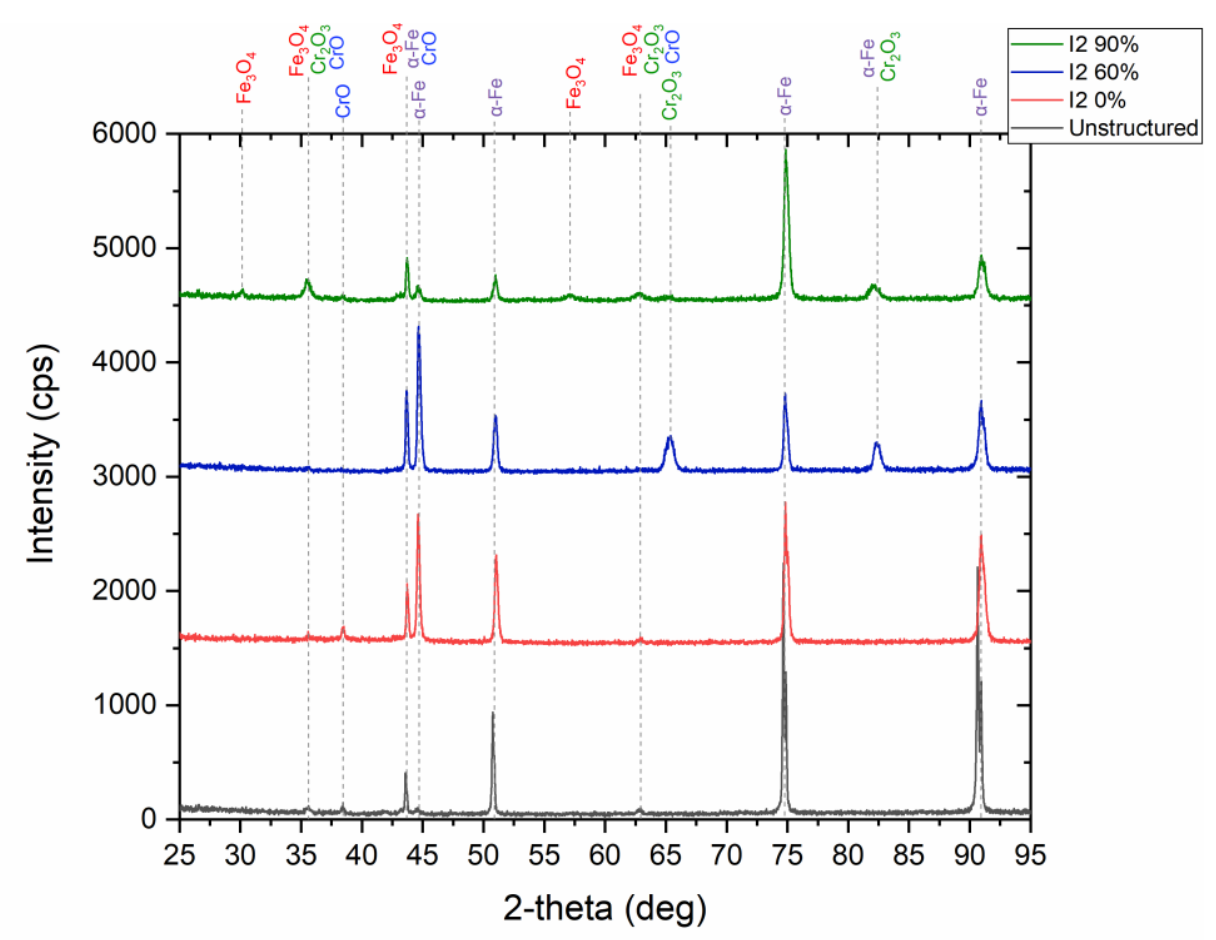

Figure 7. Phase composition of AISI 430 steel before (unstructured steel) and after laser treatment (sample $\mathrm{I}_{2} 0 \%, \mathrm{I}_{2} 60 \%, \mathrm{I}_{2} 90 \%$ ).

Because of the high chromium presence, AISI 430 steel forms a chromium oxide film on its surface, which protects the metal from aggressive chemical impact. This fact is confirmed by XRD analysis (Fig. 7), which showed that the composition of unstructured steel mostly consists of $\alpha$-Fe with presence of $\mathrm{CrO}$. The contact angle of the unstructured steel is 65 degrees, which correlates with the fact that clean metal oxides are hydrophilic (Takeda, S., et al. 1999).

In addition, the composition of the sample $\mathrm{I}_{2} 0 \%$ is similar to the unstructured one because of low temperature of laser treatment, which affects only the surface relief. The contact angle of this sample decreases, and it is corresponding with the Wenzel equation, where the hydrophilicity of the surface rises with roughness increasing (Wenzel, R.N. 1936).

At the initial stage of laser irradiation, after the increase of overlapping (sample $\mathrm{I}_{2} 60 \%$ ), the access of oxygen to the components of the steel and to chromium in particular is unlimited. Thus, $\mathrm{Cr}_{2} \mathrm{O}_{3}$ oxide is formed on the surface of the steel. This result can be explained by the fact that chromium has a greater affinity for oxygen than iron, and chemically absorbed oxygen selectively interacts with chromium ions and atoms. The change in the composition of the 
sample to $\mathrm{Cr}_{2} \mathrm{O}_{3}$ and the increase of the surface roughness due to higher temperature of laser irradiation leads to the formation of more hydrophilic surface with the contact angle being about 15 degrees.

With a higher increase of the laser exposure (sample $\mathrm{I}_{2} 90 \%$ ), iron diffuses through the existing oxide layer leading to the formation of magnetite. This result is in a good agreement with the previous results of theoretical calculations obtained by chemical thermodynamics method (Veiko, V.P. et al. 2013). The sample $\mathrm{I}_{2} 90 \%$ with $\mathrm{Fe}_{3} \mathrm{O}_{4}$ in composition has the most hydrophilic surface with the contact angle 10 degrees due to very high surface roughness.

Stability of the transition from hydrophilic to hydrophobic properties

Several laser-textured samples were left in air for one year. After that the contact angles changed as shown in Fig. 8A. As one can see in the Figure, as a result of the air exposure, the contact angles became close to the superhydrophobic ones.
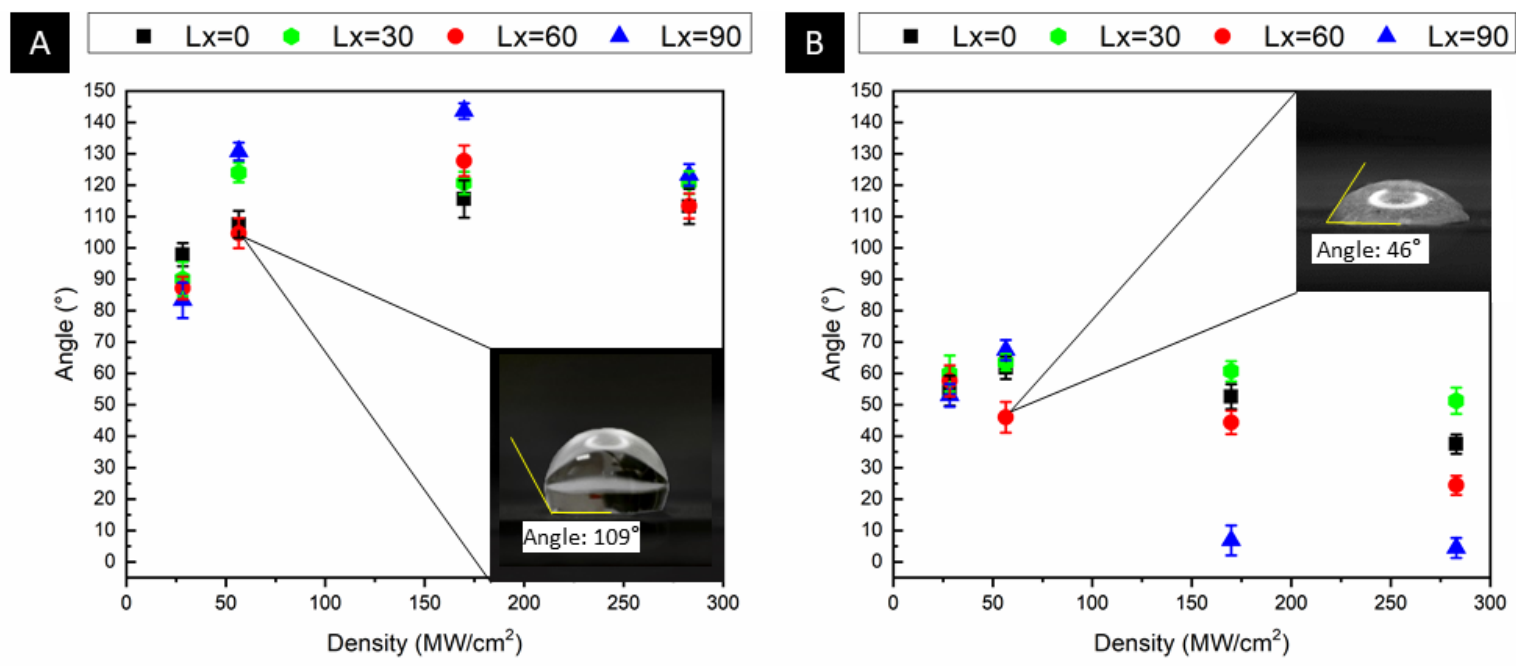

Figure 8. Contact angle as a function of laser intensity for different overlapping obtained after 1 year in air (A), after cleaning in an ultrasonic bath (1 hour, $28^{\circ}$

$$
\text { C) (B); } L_{x}=L_{y} \text {. }
$$

The transition to the hydrophobic state can be connected to the adsorption of organic compounds by metal oxides (Takeda, S., et al. 1999). The presence of such organic compounds in the atmosphere is well studied and their sources vary from anthropogenic to biological, which are associated with the vital processes of living creatures. 
However, most of the samples have different angle increment. The largest angle increment of 120 degrees corresponds to the sample $I_{2} 90 \%$, since iron oxides are the best substrates for the adsorption of organic compounds $(\mathrm{Gu}$, B. et al. 1995). Another factor affecting the increase in angle is the highest surface roughness of the sample, since the area for organic compounds adsorption is the largest.

Then these samples were placed in an ultrasonic bath with distilled water for one hour at temperature of $28{ }^{\circ} \mathrm{C}$. The angle values decreased and had tendency for acquiring the initial values (Fig. 8B). Probably, the organic compounds adsorbed by the laser treated surfaces have been washed out explaining the observed results.

Another set of samples after laser irradiation was subjected to low temperature annealing in an oven with a temperature of $100{ }^{\circ} \mathrm{C}$ for three hours. After that, the contact angle was measured. The wetting angle of the sample with all types of overlapping, except Lx $=\mathrm{Ly}=90 \%$, increased (Fig. 9).
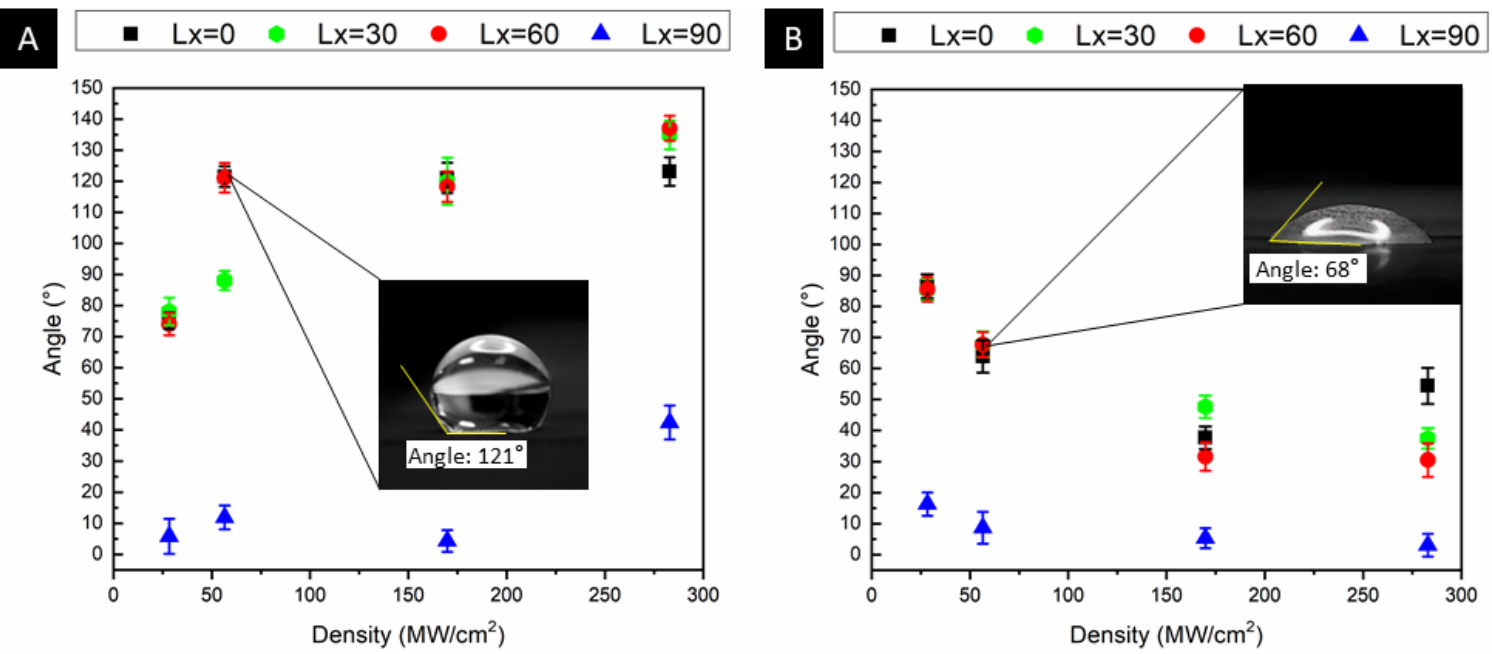

Figure 9. The dependence of contact angle from intensity with different overlapping right after low-temperature annealing ( 3 hours, $\left.100^{\circ} \mathrm{C}\right)(\mathrm{A})$, after cleaning in an ultrasonic bath $\left(1\right.$ hour, $\left.28^{\circ} \mathrm{C}\right)(\mathrm{B}) ; \mathrm{Lx}=\mathrm{Ly}$.

The number of $\mathrm{H}_{2} \mathrm{O}$ molecules in the air rose with the increase of temperature inside the oven. The most hydrophilic sample $\mathrm{I}_{2} 90 \%$ with the largest surface roughness has $\mathrm{Fe}_{3} \mathrm{O}_{4}$ in the composition, which is a good adsorbent not only for carbon, but also for water (Kietzig, A.M. et al. 2009; Joseph, Y. et al. 
2000). The most hydrophilic sample $I_{2} 90 \%$ (and other with overlapping 90\%) adsorbs $\mathrm{H}_{2} \mathrm{O}$ molecules instead of organic compounds from the ambient air. Thus, a formed layer of water prevents the carbon deposition on the surface of sample $\mathrm{I}_{2} 90 \%$. Meanwhile, other samples continue the accelerated by heating adsorption of organic compounds from the air and transfer to the hydrophobic state.

Then the samples were placed in an ultrasonic bath for one hour at a temperature of $28^{\circ} \mathrm{C}$ and the contact angle also tends to return to its original value, since the organic compounds were washed out from the surface.

In order to confirm our hypothesis about layer of water preventing the carbon adsorption on the surface of sample $\mathrm{I}_{2} 90 \%$ we conducted an experiment in oven with same condition but with higher humidity (from $70 \%$ to 95\%) (Fig. 10). It turned out that with the increase of $\mathrm{H}_{2} \mathrm{O}$ molecules other samples also keep their hydrophilic properties.

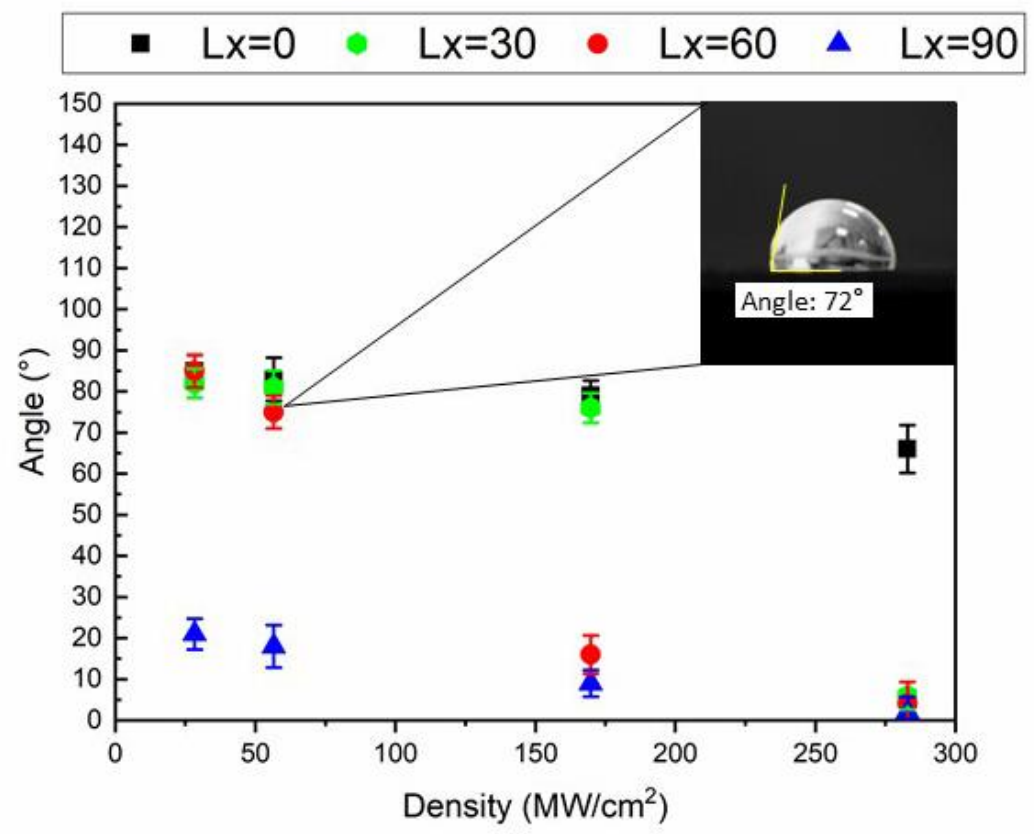

Figure 10. The dependence of contact angle from intensity with different overlapping right after low temperature annealing with increased humidity conditions $\left(3\right.$ hours, $\left.100^{\circ} \mathrm{C}\right) ; \mathrm{Lx}=\mathrm{Ly}$.

A slight increment in contact angle can be noticed only for samples treated with low overlapping. The humidity conditions are, therefore, also important for the wettability transition since the water in air may obstruct the organic compounds adsorption. Thus, to maintain low wetting angles, it is necessary to store structured 
samples in an environment with a high level of air humidity. This can reduce sample preparation time for applications of hydrophilic surfaces to a minimum, avoiding the necessity to clean structures from organic compounds in an ultrasonic bath.

\section{Summary}

In this work, the effects of morphology and composition on the wettability characteristics of AISI 430 steel have been studied. The mechanism of wettability transition has been considered for two techniques leading to an increase in the hydrophobic properties. The transition to hydrophobic state takes place because of the enhanced adsorption of organic compounds by structured metal oxides. It has been found that high humidity can obstruct the organic compounds absorption thus preserving hydrophilic surface.

After laser structuring, hydrophobic structures which have been kept in air or treated by a low-temperature annealing have been shown to be unstable the continuous influence of water. Therefore, an additional protection or coating is required to use these structures in industrial applications.

\section{Acknowledgments}

The reported study was funded by RFBR, project number 19-32-90017 and thematical map of fundamental research IPCP RAS no. 0089-2019-0017.

PHC Kolmogorov "Formalas" project operated by Campus France is gratefully acknowledged.

\section{References}

Avrămescu, R. E., Ghica, M. V., Dinu-Pîrvu, C., Prisada, R., Popa, L.: Superhydrophobic natural and artificial surfaces-A structural approach. Materials (2018). https://doi.org/10.3390/ma11050866

Bizi-Bandoki, P., Valette, S., Audouard, E., Benayoun, S.: Time dependency of the hydrophilicity and hydrophobicity of metallic alloys subjected to femtosecond laser irradiations. Applied Surface Science (2013). https://doi.org/10.1016/j.apsusc.2013.02.054 
Butev, E., Esen, Z., Bor, S.: In vitro bioactivity investigation of alkali treated Ti6Al7Nb alloy foams. Applied Surface Science (2015). https://doi.org/10.1016/j.apsusc.2014.12.005

Chantada, A., Penide, J., Riveiro, A., del Val, J., Quintero, F., Meixus, M., Soto, R., Lusquiños, F., Pou, J.: Increasing the hydrophobicity degree of stonework by means of laser surface texturing: An application on Zimbabwe black granites. Applied Surface Science https://doi.org/10.1016/j.apsusc.2016.12.196

(2017).

Daw, A.E., Kazi, H.A., Colombo, J.S., Rowe, W.G., Williams, D.W., Waddington, R. J., Thomas, D.W., Moseley, R.: Differential cellular and microbial responses to nano-/micron-scale titanium surface roughness induced by hydrogen peroxide treatment. Journal of biomaterials applications (2013). https://doi.org/10.1177/0885328212441495

Gu, B., Schmitt, J., Chen, Z., Liang, L., McCarthy, J. F.: Adsorption and desorption of different organic matter fractions on iron oxide. Geochimica et Cosmochimica Acta (1995). https://doi.org/10.1016/0016-7037(94)00282-Q

Huerta-Murillo, D., García-Girón, A., Romano, J.M., Cardoso, J.T., Cordovilla, F., Walker, M., Dimov, S.S., Ocaña, J.L.: Wettability modification of laser-fabricated hierarchical surface structures in Ti-6Al-4V titanium alloy. Applied Surface Science (2018). https://doi.org/10.1016/j.apsusc.2018.09.012

Hwang, S. J., Oh, D. J., Jung, P. G., Lee, S. M., Go, J. S., Kim, J. H., Ko, J. S.: Dry etching of polydimethylsiloxane using microwave plasma. Journal of Micromechanics and Microengineering (2009). https://doi.org/10.1088/0960$\underline{1317 / 19 / 9 / 095010}$

Joseph, Y., Ranke, W., Weiss, W.: Water on FeO (111) and Fe3O4 (111): Adsorption behavior on different surface terminations. The Journal of Physical Chemistry B (2000). https://doi.org/10.1021/jp9932012

Kietzig, A.M., Hatzikiriakos, S.G., Englezos, P.: Patterned superhydrophobic metallic surfaces. Langmuir (2009). https://doi.org/10.1021/la8037582

Kietzig, A.M., Negar Mirvakili, M., Kamal, S., Englezos, P., Hatzikiriakos, S. G.: Laser-patterned super-hydrophobic pure metallic substrates: Cassie to Wenzel wetting transitions. Journal of Adhesion Science and Technology (2011). https://doi.org/10.1163/016942410X549988

Kietziga, A. M., Mirvakilia, M. N., Kamalb, S., Englezosa, P., \& Hatzikiriakosa, S. G.: Nanopatterned metallic surfaces: their wettability and impact on ice friction. Journal of Adhesion Science and Technology (2011). https://doi.org/10.1163/016942411X555872

Kim, D., Kim, J. G., Chu, C. N.: Aging effect on the wettability of stainless steel. Materials Letters (2016). https://doi.org/10.1016/j.matlet.2016.01.107

Kolobov, Yu.R., Smolyakova, M.Yu., Kolobova, A.Yu., Ionin, A.A., Kudryashov, S.I., Makarov, S.V., Saltuganov, P.N., Zayarny, D.A., Ligachev, A.E.: Superhydrophylic Textures Fabricated by Femtosecond Laser Pulses on Submicro- and Nano-crystalline Titanium Surfaces. Laser Physics Letters (2014). https://doi.org/10.1088/1612-2011/11/12/125602 
Li, H., Wang, J.: An experimental study of abrasive waterjet machining of Ti-6Al-4V. The International Journal of Advanced Manufacturing Technology (2015). https://doi.org/10.1007/s00170-015-7245-5

Li, B. J., Li, H., Huang, L. J., Ren, N. F., Kong, X.: Femtosecond pulsed laser textured titanium surfaces with stable superhydrophilicity and superhydrophobicity. Applied Surface Science (2016). https://doi.org/10.1016/j.apsusc.2016.07.137

Lieblich, M., Barriuso, S., Ibáñez, J., Ruiz-de-Lara, L., Díaz, M., Ocaña, J.L., Alberdi, A., González-Carrasco, J.L.: On the fatigue behavior of medical Ti6Al4V roughened by grit blasting and abrasiveless waterjet peening. Journal of the mechanical behavior of biomedical materials (2016). https://doi.org/10.1016/j.jmbbm.2016.07.011

Liu K., Jiang L.: Metallic surfaces with special wettability. Nanoscale (2011). https://doi.org/10.1039/c0nr00642d

Long, J., Zhong, M., Zhang, H., Fan, P.: Superhydrophilicity to superhydrophobicity transition of picosecond laser microstructured aluminum in ambient air. Journal of colloid and interface science (2015). https://doi.org/10.1016/j.jcis.2014.11.015

Ngo, C. V., Chun, D. M.: Fast wettability transition from hydrophilic to superhydrophobic laser-textured stainless steel surfaces under low-temperature annealing. Applied Surface Science (2017).

https://doi.org/10.1016/j.apsusc.2017.03.038

Ngo, C.V., Chun, D.M.: Controlling the wetting properties of superhydrophobic titanium surface fabricated by UV nanosecond-pulsed laser and heat treatment. Nanomaterials (2018). https://doi.org/10.3390/nano8100766

Nik M.G., Movahhedy M.R., Akbari. J.: Ultrasonic-assisted grinding of Ti6Al4V alloy. Procedia CIRP https://doi.org/10.1016/j.procir.2012.04.063

Ravelingien, M., Hervent, A.S., Mullens, S., Luyten, J., Vervaet, C., Remon, J.P.: Influence of surface topography and pore architecture of alkalitreated titanium on in vitro apatite deposition. Applied Surface Science (2010). https://doi.org/10.1016/j.apsusc.2010.01.008

Rotella, G., Dillon, O.W., Umbrello, D., Settineri, L., Jawahir, I.S.:The effects of cooling conditions on surface integrity in machining of Ti6Al4V alloy. The International Journal of Advanced Manufacturing Technology (2014). https://doi.org/10.1007/s00170-013-5477-9

Sciancalepore, C., Gemini, L., Romoli, L., Bondioli, F.: Study of the wettability behavior of stainless steel surfaces after ultrafast laser texturing. Surface and Coatings Technology (2018). https://doi.org/10.1016/j.surfcoat.2018.08.030

Song, Y., Liu, Y., Jiang, H., Zhang, Y., Han, Z., Ren, L.: Biomimetic super hydrophobic structured graphene on stainless steel surface by laser processing and transfer technology. Surface and Coatings Technology (2017). https://doi.org/10.1016/j.surfcoat.2017.08.031

Takeda, S., Fukawa, M., Hayashi, Y., Matsumoto, K.: Surface OH group governing adsorption properties of metal oxide films. Thin Solid Films (1999). https://doi.org/10.1016/S0040-6090(98)01152-3 
Veiko, V.P., Slobodov, A.A., Odintsova, G.V.: Availability of methods of chemical thermodynamics and kinetics for the analysis of chemical transformations on metal surfaces under pulsed laser action. Laser Physics (2013). https://doi.org/10.1088/1054-660X/23/6/066001

Wennerberg, A., Svanborg, L.M., Berner, S., Berner, S., Andersson, M.: Spontaneously formed nanostructures on titanium surfaces. Clinical oral implants research (2013). https://doi.org/10.1111/j.1600-0501.2012.02429.x

Wenzel, R.N: Resistance of solid surfaces to wetting by water. Industrial \& Engineering Chemistry (1936). https://doi.org/10.1021/ie50320a024

Wyman, P.: Hydrophilic coatings for biomedical applications in and ex vivo. Coatings for Biomedical Applications (2012). https://doi.org/10.1533/9780857093677.1.3

Yang, Z., Liu, X., Tian, Y.: Fabrication of super-hydrophobic nickel film on copper substrate with improved corrosion inhibition by electrodeposition process. Colloids and Surfaces A: Physicochemical and Engineering Aspects (2019). https://doi.org/10.1016/j.colsurfa.2018.10.024 